\title{
Recent changes in the frequency of plant species and vegetation types in Scania, S Sweden, compared to changes during the twentieth century
}

\author{
Torbjörn Tyler $^{1}$ (D) - Stefan Andersson ${ }^{2} \cdot$ Lars Fröberg $^{3} \cdot$ Kjell-Arne Olsson $^{3}$. \\ Åke Svensson ${ }^{3}$. Ola Olsson ${ }^{2}$ (D)
}

Received: 20 June 2019 / Revised: 28 October 2019 / Accepted: 19 November 2019 /

Published online: 26 November 2019

(c) The Author(s) 2019

\begin{abstract}
Based on data from three surveys of the vascular flora of the province of Scania, southernmost Sweden, conducted 1938-1971, 1987-2006 and 2008-2015, we analyse the change in frequency of individual species and groups of species associated with particular vegetation types. A majority of all species have experienced a change in frequency since 1938, and this turnover has continued in recent decades. The species showing the most dramatic declines since 1987 represent a mixture of arable weeds, grassland species and ruderals, but excludes forest species. In contrast, a majority of the most increasing species are escapes from cultivation that thrive under shaded conditions. The vegetation types showing the largest decreases since 1987 are all open seminatural grasslands and wetlands, while the vegetation types performing best are wooded. All vegetation types increasing since 1987 also increased during the 1900s; however, species of wooded types performed relatively better in recent decades, as opposed to the minimal increase observed for species of vegetation strongly influenced by human activities. Among decreasing vegetation types, those that have received much attention from conservationists, e.g. sand-steppe and calcareous fens tend to perform relatively better now than during the 1900 s, while those that have received less attention, e.g. poor fens, oligotrophic waters and heaths, now comprise the most rapidly declining vegetation types. A majority of the species that decreased 1938-1996 also decreased 1987-2015, but, in general, species shown to have increased during the 1900s have not continued to increase.
\end{abstract}

Communicated by David Hawksworth.

Electronic supplementary material The online version of this article (https://doi.org/10.1007/s1053 1-019-01906-5) contains supplementary material, which is available to authorized users.

Torbjörn Tyler

torbjorn.tyler@biol.lu.se

1 The Biological Museum, Department of Biology, Lund University, P.O. Box 117, 22100 Lund, Sweden

2 Biodiversity Unit, Department of Biology, Lund University, Ecology Building, 22362 Lund, Sweden

3 Lund Botanical Society, c/o Wigermo, Fästningsgatan 19B, 29134 Kristianstad, Sweden 
Keywords Citizen science $\cdot$ Conservation $\cdot$ Land use $\cdot$ Vegetation management

\section{Introduction}

Anthropogenic factors such as changing land use, pollution and climate warming have caused significant changes in the biodiversity across the world and have gradually become a major concern for both conservationists and policy makers in Europe (e.g. Bernes 2011-2012). Still, there is a lack of relevant data and monitoring schemes for most groups of organisms that may be affected (Bernhardt-Römermann et al. 2015). Vascular plants constitute the main primary producers of a majority of terrestrial ecosystems and therefore have a profound influence on the distribution and diversity of most other organisms (e.g. Berg 2002; Carvell et al. 2006; Jonason et al. 2010). At the same time, plant species are sensitive to a wide range of changes in the environment, often to the extent that entire plant communities or regional species pools become affected (e.g. Arts 2002; Maad et al. 2009; Cousins et al. 2015; Hedwall and Brunet 2016). Monitoring changes in frequency and diversity of vascular plants should thus have a high priority (Tyler et al. 2018; Nielsen et al. 2019). However, there are still very few studies of changes in frequency of all plant species on regional or national scales; the studies of Mennema et al. (1980-1989), Rich and Woodruff (1996), Tyler and Olsson (1997), Maad et al. (2009) and Nielsen et al. (2019) are almost the only examples, and there are virtually no plant studies that span multiple monitoring dates/surveys.

Scania, the southernmost province of Sweden, is in several ways ideal for studying temporal changes in biodiversity. Results from Scania may be generalized to large parts of Europe (Tyler et al. 2018) since the province is situated approximately in the middle of the south-north extent of the European Continent, on the border between the nemoral and boreonemoral vegetation zones, and comprises subregions with contrasting geomorphology as well as current and past land use (Andersson and Weimarck 1996). Thanks to the efforts of the Lund Botanical Society and its volunteer recorders, the flora of the province is very well known from repeated surveys. In 2008, the Project 'Millora' ("Miljö- och floraövervakning i Skåne", i.e. "Environmental and floristic monitoring of Scania") was launched by the Society with the aim at documenting and analysing contemporary changes in the flora. In a previous publication, viz. Tyler et al. (2018), we used the Millora data to infer the causes of recent floristic changes by superimposing information about speciesspecific traits. We then showed that the main drivers of broad-scale changes during the most recent decades have been climatic warming and changes in land use, in particular declining cattle grazing and reduced soil disturbance from agricultural activities (Tyler et al. 2018). Here, we instead focus on the effects these drivers have had on individual species and species associated with particular vegetation types. In addition, we compare changes in the frequency of species and vegetation types during the very last decades with those previously documented in the 1900 s. 


\section{Materials and methods}

\section{Study area}

Scania is the southernmost province of Sweden, covering an area of ca. $11,000 \mathrm{~km}^{2}$, centered at around $56^{\circ} \mathrm{N}, 13^{\circ} 30^{\prime} \mathrm{E}$. The basic climatic conditions during the national reference period 1961-1990 were: annual mean temperature $6.3-8.2^{\circ} \mathrm{C}$, mean temperature of the coldest month $-2.3-0.1{ }^{\circ} \mathrm{C}$, and annual precipitation $480-915 \mathrm{~mm}$ (Tyler 2007). The province is geomorphologically and phytogeographically diverse (Andersson and Weimarck 1996; Persson and Tyler 2007). Almost half of the province comprises plains with more or less calcareous clayey till overlaying chalk or shale bedrock, while the other more upland half (50-200 m a.s.1.) is covered by more or less strongly acid sandy till overlaying siliceous bedrock (Persson and Tyler 2007). In the east, there are also significant areas with calcareous sand deposits. The plains are mainly used for agriculture, with some intermixed, fragmented and largely unmanaged deciduous broadleaf forests; in contrast, the uplands are nowadays mainly covered by mostly intensively managed mixed deciduous/conifer forests and peatlands, with some intermixed and fragmented pastures and arable land. In the past, however, agriculture and, in particular, cattle breeding used to dominate in the uplands.

\section{The data sets}

This study is based on comparisons of the results from three surveys of the flora of Scania, undertaken in 1938-1971, 1987-2006 and 2008-2015 by the Lund Botanical Society. The two first surveys were compared by Tyler and Olsson (1996), but here the same data is partially re-analysed to provide results that can be directly compared with those from the two most recent surveys. The surveys mainly concerned taxa with the rank of species, but some intraspecific taxa, as well as a few species complexes in taxonomically critical groups, were also included; for simplicity, in the following text all taxa will be referred to as species.

Survey 1 (1938-1971) was summarised by Weimarck and Weimarck (1985). The basic units of this survey were 'sections' of somewhat variable size $\left(7-10 \mathrm{~km}^{2}\right)$ mostly delimited by roads, water courses and administrative borders, and the volunteer surveyors (mostly students and researchers in Systematic Botany at Lund University) were asked to compile lists of all wild plant species found in each section, but excluding the most common ones. However, some recorders luckily chose to include all species and only areas with such complete species lists were chosen for the present analyses. The list of species to be recorded was somewhat modified during the surveying period and introduced species and garden escapes were not always considered.

Survey 2 (1987-2006) was summarised by Olsson and Tyler (2007). The basic units of this survey were $19892.5 \times 2.5 \mathrm{~km}$ (i.e. $6.25 \mathrm{~km}^{2}$ ) large grid-squares defined by the Swedish National Grid and the volunteer surveyors were asked to compile complete lists of all plant species found in each grid-square. The list of taxa to be recorded was standardised and for a considerable number of species that were considered difficult to identify only records documented by vouchers (normally herbarium specimens) verified by appointed experts were accepted. All species found in places where they were not, or no longer, intentionally cultivated (i.e. including ephemerals and garden escapes) were included. 
Survey 3 (2008-2015), viz. the Project Millora, was recently summarized in Tyler et al. (2018). In this project, 200 grid-squares from survey 2 were re-surveyed. The gridsquares surveyed were selected by a geographically stratified randomization procedure to ensure that the results would be representative for the province as a whole. The methods and instructions given to the recorders were the same as during survey 2, apart from some simplifications of the standardised species list (some subspecific taxa omitted) and the suspension of the documentation requirement for some species now considered accurately described in the recent literature. A majority of the recorders taking part in survey 3 were also active during survey 2 .

Although efforts were concentrated to particular grid-squares in particular years during all three surveys, data on species observations were accumulated throughout the survey period, thus making it impossible to more precisely define the time-span of individual comparisons. However, it was possible to calculate the average age difference between any two observations included in a particular pair of surveys and we used these when estimating the rate of changes.

\section{Comparison of survey 1 and 2}

Partial results of survey 2 (until 1995) and results of survey 1 were compared by Tyler and Olsson (1997) with the aim of estimating the change in frequency of individual species, groups of species with similar habitat preferences and species with particular traits and growth requirements. However, since the methods of the two surveys compared were incongruent in several respects, some restrictions and assumptions had to be made. The comparison was restricted to $1242.5 \times 2.5 \mathrm{~km}$ grid-squares selected on the basis of availability and completeness of data resulting in geographically slightly biased data (in particular the coastal regions were not well represented; see map in Tyler and Olsson 1997). The basic assumptions of these analyses were (i) that no general changes in species richness had taken place between the surveys (i.e. changes for individual species were calculated as relative to those of other species), and (ii) that differences in surveying intensity and in the size of the basic units of the two surveys could be compensated by applying a binomial regression model (for more details, see Tyler and Olsson 1997). In the study presented here, we accepted these assumptions and limitations, and re-ran the analyses of Tyler and Olsson (1997) with one major modification: in our re-analysis we considered only presence/absence in individual grid-squares, as opposed to Tyler and Olsson (1997) who also considered the number of records of the same species in each grid-square (abundance). Furthermore, we used a more modern approach to estimate the statistical significance of the difference between the two surveys.

The statistical significance of the estimated changes, i.e. the difference between the observed number of presences in grid-squares in survey 2 and the number of grid-squares with presences in survey 1 , as predicted by the model based on the observed numbers, was tested with two-sided binomial tests (function binom.test in $\mathrm{R}$ 3.6, R Core Team 2019). That is, we used the number of grid-squares with a species in the second survey as the number of successes, the total number of grid-squares compared (124) as the number of trials, and the proportion of grid-squares with the species in the first survey as the hypothesized probability of success under the null hypothesis of no change in frequency. No attempts were made to adjust $p$ values for multiple tests since the aim was to test for changes for individual species rather than estimating the number of species with significant changes, i.e. each species was considered as an independent hypothesis to be tested, and 
the significance levels for changes at the species level were applied mostly to arrive at comparable and unbiased thresholds for comparing pools of species associated with different vegetation types and during different time periods. After the exclusion of species not considered resident in the province in 2007 (Olsson and Tyler 2007) following the definition of Jonsell (2004), of some non-indigenous species not reliably recorded during survey 1, and of a few taxonomically problematic species, estimates of changes in frequency were calculated for 1047 species. The total number of records from survey 1 and survey 2 included in the analyses was 30,246 (39,840 as re-calculated by the model) and 40,058, respectively. The mean time-span between these surveys was 41 years and any difference should thus mostly reflect changes taken place during the latter half of the twentieth century, although some changes dating back to the 1930s may also have influenced the results.

\section{Comparison of surveys 2 and 3}

The results of surveys 2 and 3 were readily comparable by simply calculating the number of grid-squares with presences and absences of individual species in each of the two surveys and testing for differences using binomial tests, as above but with the total number of grid-squares being 200. Again, each species was considered as an independent hypothesis to be tested and therefore no correction for multiple testing was made. The mean time-span between the two surveys was 13 years and the result should thus mostly reflect changes taken place during the twenty first century. The total number of records from surveys 2 and 3 included in the analyses was 76,029 and 71,165, respectively. Thus, survey 3 resulted in $6.4 \%$ fewer records than survey 2 . Still, the mean change per species in frequency between the two surveys was negligible $(+0.3 \%)$, indicating that the second survey resulted in fewer records of a relatively small number of common species but more records of a higher number of more rare species (for details, see Tyler et al. 2018).

After exclusion of species not considered resident in the province in 2007, estimates of changes in frequency were calculated for 1392 species.

For each species, we calculated colonization rates and extinction rates in the 200 gridsquares. Colonization rate was calculated as the number of grid-squares lacking the species in survey 2 but occupied by it in survey 3, divided by the total number of grid-squares occupied by the species in survey 3 , i.e. the proportion of squares currently occupied that have become so in between the surveys. Extinction rate was similarly calculated as the number of grid-squares lacking the species in survey 3 but not in survey 2, divided by the total number of squares occupied in survey 2, i.e. the proportion of squares that had lost the species from surveys 2 to 3 . For both quantities we estimated $95 \%$ confidence intervals as 2.5 and $97.5 \%$ percentiles of a binomial distribution with the number of occupied grid-squares (during survey 2 for extinction and survey 3 for colonization rate) as number of trials, and extinction and colonization rates as probability. To facilitate comparisons among pairs of surveys spanning different time periods, the rate of change per decade was calculated by division with the mean time span between the surveys compared (41 years between surveys 1 and 2, and 13 years between surveys 2 and 3). The rate of change was thus calculated as change in the proportion of occupied grid-squares, but to facilitate conclusions and discussion concerning individual species, species-wise changes relative to the frequency of the species in the oldest survey in each comparison were also calculated and presented.

To assess the spatial stability of the distribution of each species we calculated Sörensen's similarity index as twice the number of grid-squares occupied by the species in both 
surveys, divided by the sum of the number of squares occupied in survey 2 and the number of squares occupied in survey 3 . When this index is high (close to 1) it means that the species has been occupying largely the same grid-squares in both surveys, and when it is low (close to 0 ) it means that different grid-squares are occupied in the two surveys, even if the total numbers can be similar.

\section{Comparisons across all surveys}

In order to ascertain whether changes for individual species during the most recent decades is a continuation of those seen during the twentieth century we calculated the number of species showing significant increases, decreases or opposite trends between surveys 1 and 2 and between surveys 2 and 3, respectively. These numbers were used to calculate a $\chi^{2}-$ test of independence among categories (Table 1). To ease the interpretation, the estimated frequency changes between surveys 1 and 2 and between surveys 2 and 3 were rescaled as change per decade by dividing with the mean timespan between pairs of surveys (4.1 and 1.3 decades, respectively) for the purpose of plotting the results (Fig. 1). To avoid noise arising from highly uncertain estimates, only species with documented occurrences in at least 5 grid-squares in all three surveys were included, leaving 659 species for this analysis.

\section{Analyses of vegetation changes}

In order to obtain estimates of change for different vegetation types, all taxa were ascribed to one or more of 30 vegetation types based on the definitions and information provided by Olsson and Tyler (2007). These, in turn, were based on information provided by the surveyors during survey 2 and should accurately reflect the ecology of the species as realised in the province 1987-2006. Changes for species associated with a similar list of vegetation types was provided already by Tyler and Olsson (1997), but the lists of taxa assigned to each vegetation type has since then been significantly revised and improved, making it necessary to re-analyse the data. The mean change in frequency of species (per decade) assigned to each vegetation type was compared between surveys 1 and 2 and between surveys 2 and 3. As an alternative, the same was done with species weighted by their frequency (giving higher weight to species with many records in the total data). In both cases, we were only interested in relative differences between vegetation types, and therefore we first centred the data such that overall the average change in frequency of all species between two surveys was set to 0 . (As described above, this was necessary also to evade the differences in surveying methods of surveys 1 and 2, cf. Tyler and Olsson 1997.) The mean and confidence intervals of centred frequency changes was then calculated for each vegetation type, and differences from the expectation of no change (0) was tested using one-sample t-tests. The proportion of species of each vegetation type showing statistically significant increases or decreases was also calculated.

Table 1 Number of species that significantly decreased, remained stable, or significantly increased between surveys 1 and 2 and between surveys 2 and 3

\begin{tabular}{lccc}
\hline & \multicolumn{2}{c}{ Change between surveys 1 and 2 } \\
\cline { 2 - 4 } & Decrease & Stable & Increase \\
\hline Change between surveys 2 and 3 & & \\
Increase & 0 & 16 & 17 \\
Stable & 135 & 218 & 131 \\
Decrease & 72 & 107 & 76 \\
\hline
\end{tabular}




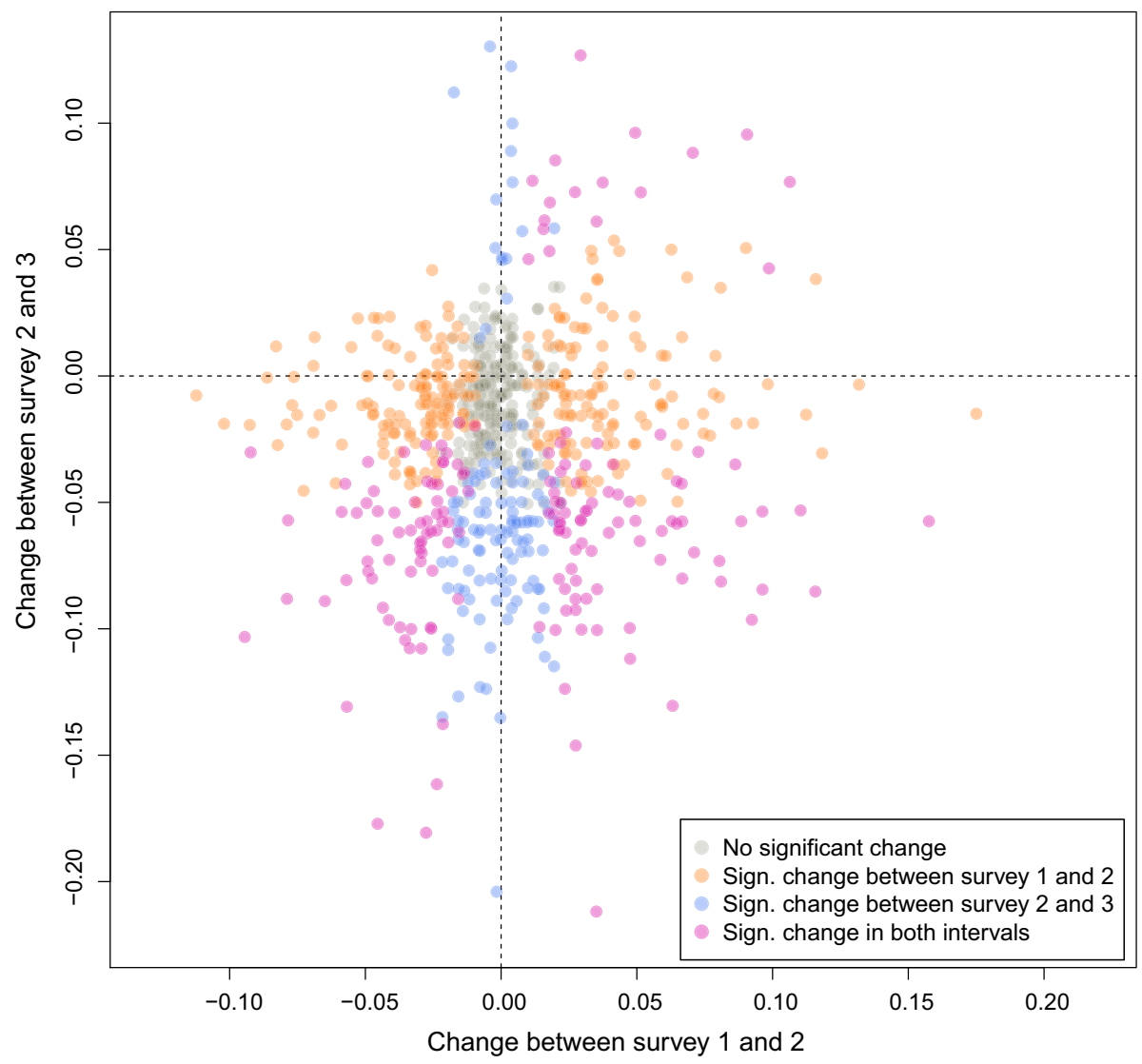

Fig. 1 Relationship between the change in frequency per decade of individual species between surveys 1 and 2 (i.e. between 1938-1975 and 1987-1995) and between surveys 2 and 3 (1987-2016 and 2007-2015). Statistically significant changes for individual species are shown by different colours as per the legend

All statistical calculations were carried out in R 3.6 (R Core Team 2019). The complete data and results for all species, including observed frequency changes and Sörensen's similarity index, is available as Supplementary Materials 1 and 2.

\section{Results}

Between survey 1 (1938-1971) and the first half of survey 2 (1987-1995), a significant relative change in frequency was observed for 546 out of 1220 analysed vascular plant species, of which 295 species decreased and 251 species increased (see Supplementary Material 2 for results for individual species). Between the whole survey 2 (1987-2006) and survey 3 (2008-2015), we documented significant (absolute) changes in the frequency of 475 out of 1392 analysed species; 320 species decreased and 155 species increased.

The changes in frequencies are summarized in Fig. 1 and Table 1 for the 772 species occurring in at least 5 grid-squares during both surveys compared. As many as 554 species showed significant changes in frequency between either pair of surveys, 
Fig. 2 Per decade rate of change in frequency (black) for the 70 species with the highest significant $\downarrow$ $(\mathrm{P}<0.05)$ rate of decrease during the period 1987-2015. Red dots are rates of losses from grid squares, and blue dots are colonization rates. Error bars show $95 \%$ confidence intervals in all cases. Numbers to the right indicate the number of occupied grid squares 1987-2006, number of occupied grid squares 2008-2015, and the change in frequency of the species relative to the first time period

and changes for individual species between one pair of surveys was not independent of changes in the other pair $\left(\chi^{2}=16.2, \mathrm{df}=4, \mathrm{P}=0.003\right)$. Specifically, there were more species increasing both between surveys 1 and 2 and between surveys 2 and 3 , than expected by chance (Table $1 ; 17$ vs. 9.6, $\chi^{2}=5.76$, $\mathrm{df}=1, \mathrm{P}=0.016$ ), and there were no species declining between surveys 1 and 2 but increasing between surveys 2 and 3 , whereas 8.8 species would be expected by chance if changes in the two periods were independent (Table $1 ; \chi^{2}=8.84, \mathrm{df}=1, \mathrm{P}=0.003$ ). The remaining seven numbers in Table 1 are very close to expectations if changes between pairs of surveys were independent $\left(\chi^{2}\right.$ between 0.08 and $\left.0.63, \mathrm{P}>0.5\right)$. That is, species that declined between surveys 1 and 2 either continued to decline or stabilized between surveys 2 and 3, but never increased. Those that were stable between the first pair of surveys were as likely to remain stable or increase or decrease, as any other species, between the latter surveys. Species that increased between surveys 1 and 2 were more likely to continue to increase than other species, but the total number of species increasing between surveys 2 and 3 is low.

The species showing the largest estimated changes between surveys 2 and 3 are shown in Figs. 2 and 3, together with colonization and extinction rates in squares. The complete list of species-wise comparisons, including Sörensen similarity indices are available as Supplementary Materials 1 and 2. The most drastic decline in terms of the absolute number of grid squares with occupied was estimated for Malus sylvestris, but this particular case may be due to taxonomic problems making the data unreliable (Tyler et al. 2007; expert-verified vouchers were mandatory for this species during survey 3 but not during survey 2). All other taxa showing drastic changes are taxonomically unproblematic and/or have been verified by experts. Relative to their frequency in survey 2, the most drastic statistically significant changes were observed for Botrychium lunaria, Crepis tectorum, Dactylorhiza maculata ssp. maculata, Veronica opaca and Raphanus raphanistrum all of which decreased by more than $70 \%$, while the largest relative increases were observed for Filago vulgaris, Cotoneaster bullatus, C. dielsianus, Hyacinthus $\times$ variabilis, Alchemilla mollis, Lamiastrum galeobdolon subsp. argentatum and Crocus tommasinianus, all of which increased by more than $200 \%$.

Between survey 1 (1938-1971) and the first half of survey 2 (1987-1995), the mean change in frequency of associated species (Fig. 4) increased significantly for 7 vegetation types, with ruderal land and base-poor wastelands and road verges showing the largest increase (both ca. $2 \%$ per decade), and decreased significantly for 13 vegetation types, with sand-steppe and various types of mire and fen vegetation showing the largest decrease (ca. $2 \%$ per decade).

Between the two most recent surveys (1987-2006 vs. 2008-2015), the mean change in frequency of associated species increased significantly for only three vegetation types (Fig. 4): hedges and shrublands, etc., base-rich nemoral deciduous forest and base-rich swamp forest (1-2\% increase per decade), while the frequency significantly decreased for 15 vegetation types with oligotrophic waters, arable land, moist seminatural meadows, and acidic and intermediate fens being most extreme (all decreasing by ca. 2-3\% per decade). 
Malus sylvestris Myosotis laxa ssp. caespitosa Galeopsis speciosa Crepis tectorum Anthemis arvensis Urtica urens Lamium amplexicaule Stellaria palustris Mentha arvensis Rubus saxatilis Alopecurus pratensis Carex panicea Juncus filiformis Nardus stricta Teesdalia nudicaúlis Thlaspi arvense Erysimum cheiranthoịdes Carex pairae

Sălix pentandra Sonchus arvensis Crepis paludosa

Galium uliginosum

Persicaria lapathifolia:ssp. pallida

Galium boreale

Lychnis flos-cuculi

Aethusa cynapium

Briza media

Saxifraga granulata

Hylotelephium telephịm ssp. maximum

Sinapis arvensis

Succisa pratensis

Alopecurus geniculatus

Carum carvi

Comarum palustre

Epilobium tetragonum

Juncus bufonius

Lolium multiflorum

Luzula multiflora

Polygala vulgaris

Salix repens ssp. repẹs

Senecio sylvaticus

Campanula rapunculöides

Euphorbia helioscopia

Scorzonera humilis

Viola palustris

Caltha palustris

Carex leporina

Fallopia convolvulus

Myosotis scorpioides

Schedonorus pratensis

Stachys palustris

Valeriana dioica

Dactylorhiza maculata ssp. maculata

Juncus bulbosus

Draba verna

Festuca ovina

Galeopsis tétrahit

Plantago major ssp. majo

Potentilla erecta

Syringa vulgaris

Vicia hirsuta

Calystegia sepium ssp. sepium

Armoracia rusticana

Bidens tripartita

Centaurea scabiosa

Cerastium semidecandrum

Crataegus laevigata

Euphorbia cyparissias

Myosotis ramosissima

Rhinanthus minor
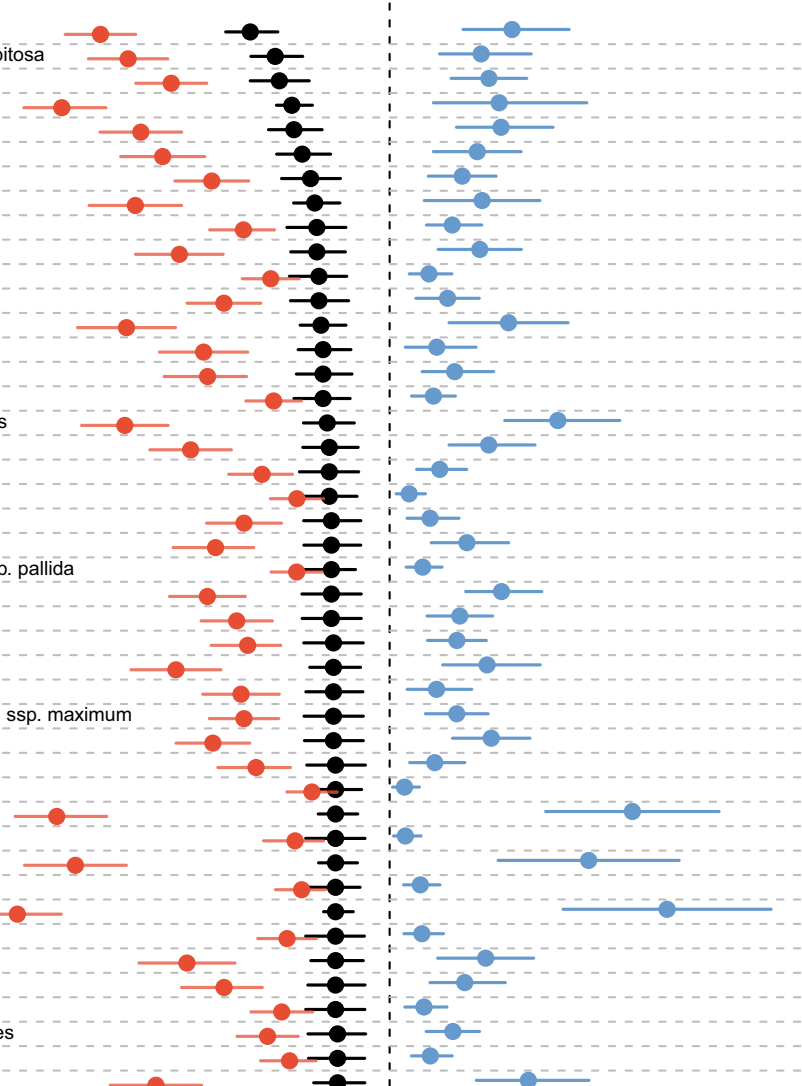

$118 \quad 51-57 \%$

$105-50-52 \%$

$141-88-38 \%$

$\begin{array}{lll}66 & 19 & -71 \%\end{array}$

$102-56-45 \%$

$99-57-42 \%$

$124-86-31 \%$

$72-36-50 \%$

$148 \quad 113-24 \%$

$\begin{array}{lll}95 & 60 & -37 \%\end{array}$

$161-127-21 \%$

$113-79-30 \%$

$\begin{array}{lll}68 & 35 & -49 \%\end{array}$

$85-53-38 \%$

$96-64-33 \%$

$165133-19 \%$

$77-47-39 \%$

$\begin{array}{lll}92 & 63-32 \%\end{array}$

$137 \quad 108-21 \%$

$157128-18 \%$

$100 \quad 72-28 \%$

$98-70-29 \%$

$179151-16 \%$

$121 \quad 93-23 \%$

$117-89-24 \%$

$126-99-21 \%$

$\begin{array}{lll}74 & 47 & -36 \%\end{array}$

$98-71-28 \%$

$120-93-22 \%$

$113 \quad 86-24 \%$

$109-83-24 \%$

$166-140-16 \%$

$50-24-52 \%$

$132106-20 \%$

$49-23-53 \%$

$175149-15 \%$

$38-12-68 \%$

$142116-18 \%$

$78-52-33 \%$

$98-72-27 \%$

$135109-19 \%$

$150125-17 \%$

$158133-16 \%$

$73 \quad 48-34 \%$

$125100-20 \%$

$161137-15 \%$

$150-126-16 \%$

$190-166-13 \%$

$167143-14 \%$

$154130-16 \%$

$145121-17 \%$

$105-82-22 \%$

$28-5-82 \%$

$67-44-34 \%$

$182159-13 \%$

$172 \overline{149}-13 \%$

$171148-13 \%$

$125102-18 \%$

$145122-16 \%$

$160137-14 \%$

$160138-14 \%$

$80-58-28 \%$

$141119-16 \%$

$100 \quad 78-22 \%$

$124102-18 \%$

$151-129-15 \%$

$12199-18 \%$

$50-28-44 \%$

$128 \quad 106-17 \%$

$95-73-23 \%$

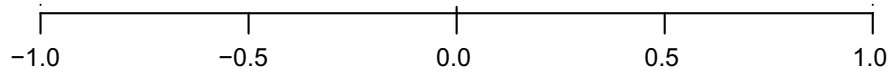

Rates 
Fig. 3 Per decade rate of change in frequency (black) for the 70 species with highest significant $(\mathrm{P}<0.05)$ rate of increase during the period 1987-2015. Red dots are rates of losses from grid squares, and blue dots are colonization rates. Error bars show $95 \%$ confidence intervals in all cases. Numbers to the right indicate the number of occupied grid squares 1987-2006, number of occupied grid squares 2008-2015, and the change in frequency of the species relative to the first time period

Weighting species by their frequency before averaging over vegetation types suggests largely the same trends (Fig. 5) with the same biggest winners and losers; however, the rank order of the estimated changes is in some cases rather different.

When comparing the trends for species of different vegetation types between the two pairs of surveys (Figs. 4, 5) it is clear that large changes in the relative performance of vegetation types have taken place. Species of arable land, base-poor wastelands and road verges, sandy sea shores, moist seminatural meadows and acid nemoral forest have been doing much worse during recent decades than during the 1900s. In contrast, species of base-rich forests and swamp forests, base-rich fens, sand-steppe and steppe-like meadows appear to perform considerably better now than during the 1900s although the latter three vegetation types are still declining.

\section{Discussion}

\section{Species-level trends}

Our results show rapid and far-reaching changes in the vascular flora of southernmost Sweden, both during the 1900 s and during the most recent decades. A majority of all plant species have experienced a change in frequency since 1938, and this turnover of the species pool appears to have continued in recent decades. In previous analyses of data from the same surveys but using species-specific traits as proxies for environmental drivers, the main drivers of floristic changes during 1938-1996 were inferred to be eutrophication/ nitrogen deposition and increasing drainage of the landscape (Tyler and Olsson 1997), while the main drivers of changes during 1987-2015 appeared to be climatic warming and decreasing management and disturbance from grazing and agricultural practices (Tyler et al. 2018). A recent study based on data from other provinces of Sweden also concluded that climatic changes have had a significant effect on changes in the flora during the last century (Auffret and Thomas 2019). The spread of recently introduced/immigrated species that may be considered invasive make up for a large proportion of the changes observed (and was also identified as a major factor in the analyses of Tyler et al. 2018); however, it is difficult to analyse to what extent their expansion is related to changes in the environment or caused by the simple fact that they have not been present and thus not able to spread before (Tyler et al. 2015, 2018).

The species showing the most dramatic declines during the most recent decades (Fig. 2 and Supplementary Material) are mostly a mixture of arable weeds of relatively less fertile soils (e.g. Anthemis arvensis, Galeopsis speciosa, Crepis tectorum, Lamium amplexicaule, Thlaspi arvense, Erysimum cheiranthoides, Raphanus raphanistrum) and species of mown or grazed seminatural grasslands (e.g. Nardus stricta, Carex pairae, Galium uliginosum, G. boreale, Briza media, Succisa pratensis, Botrychium lunaria, Dactylorhiza maculata subsp. maculata). This excludes forest species or other species that are not associated with the agricultural or urban landscape, stressing the importance of changes in land use for the changes observed (Bernes 2011-2012; Auffret and Thomas 2019). 


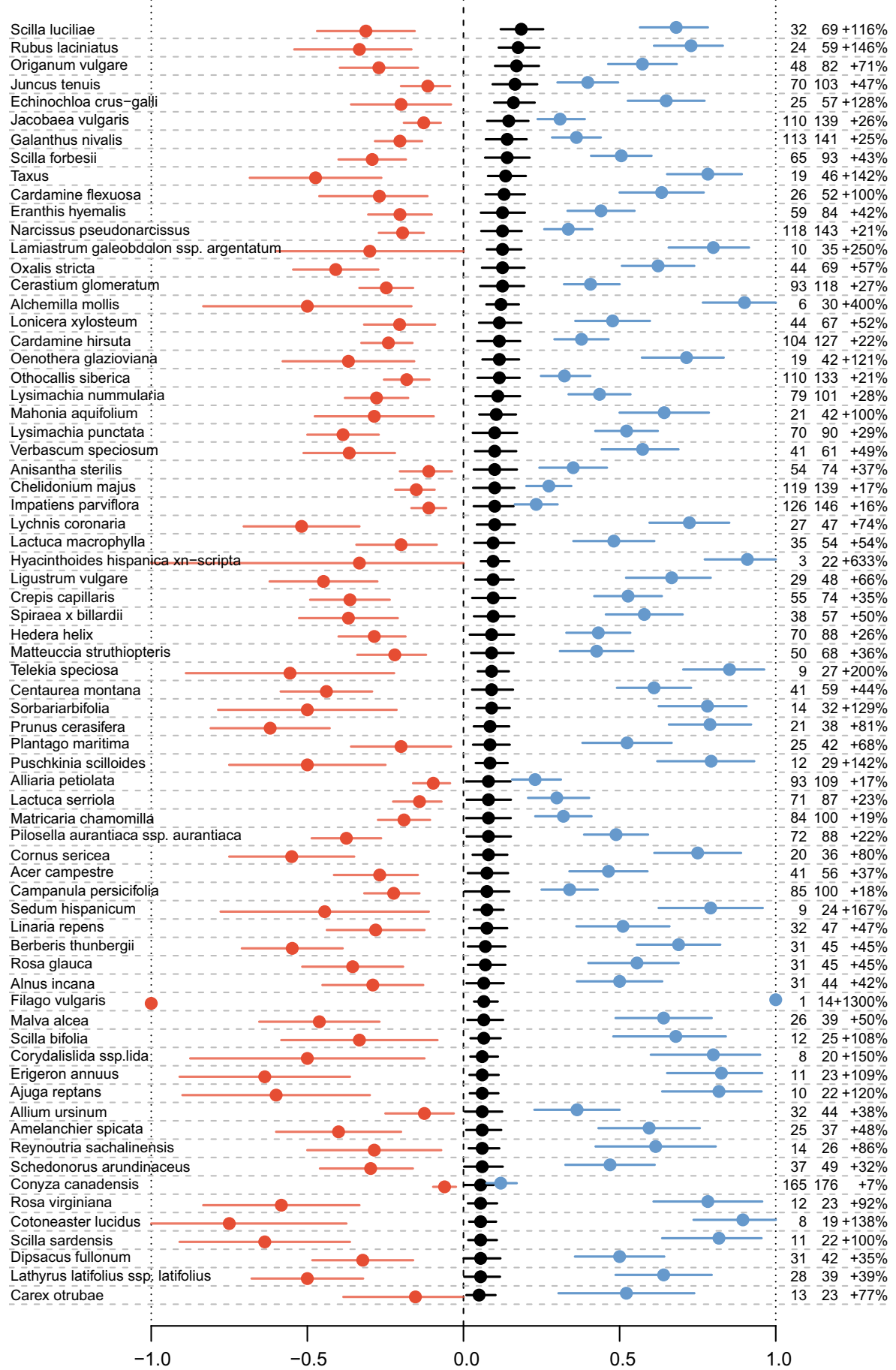

Rates 
Fig. 4 Mean relative change in frequency per decade with 95\% confidence intervals, of species associated with different vegetation types during the two time periods 1938-1995 (open circle) and 1987-2015 (filled circle). The number of species included for each vegetation type and the statistical significance of the change during each of the two time periods are indicated to the right. All species included are given the same weight

Also many very common species in open/agricultural landscapes show significant declines, although to a smaller relatively degree (Supplementary Material). Species like Alopecurus geniculatus, Euphorbia helioscopia, Caltha palustris, Solidago virgaurea, Festuca ovina, Draba verna, Fallopia convolvulus and Achillea ptarmica were recorded in almost all grid-squares during 1987-2006, but have since declined by 10-16\% and are now absent from parts of the province. In contrast, the vast majority of the most rapidly increasing species (Fig. 2 and Supplementary Material) represent escapes from cultivation that thrive under somewhat shaded conditions in hedges and forests, e.g. Scilla luciliae, Galanthus nivalis, Lysimachia nummularia and L. punctata, and woody species that are spreading from cultivated stands, e.g. Mahonia aquifolium, Taxus spp., Ligustrum vulgare, Prunus cerasifera, Cornus sericea, Spiraea spp., Amelanchier spp. and Cotoneaster spp. Among woody cultivated species, it is notable that it is mostly those with bird-dispersed red fleshy fruits that show very rapid increases (Tyler 2019). All these species are considered as invasive alien species in the region (Tyler et al. 2015), but their rapid increase in frequency may at the same time be indicative of changes in the environment and land use. The only species with a pre-1700 history in the province that have increased by more than $100 \%$ in recent decades are Filago vulgaris, growing on sandy-gravelly waste lands and rapidly expanding since its near-extinction in the late 1900s, and Echinochloa crus-gallii and Cardamine flexuosa, which are both weeds of gardens and other cultivated lands and based on their historic geographic ranges and phenology they may be assumed to be strongly favoured by longer and warmer summers and milder winters, respectively. However, some native species of forests and shrublands also show significant increases, e.g. Chelidonium majus, Alliaria petiolata, Campanula persicifolia and Allium ursinum. Furthermore, it should be pointed out that since the analysis is based on a fixed number of relatively large grid-squares, increases for already very common species may be difficult to detect.

The species showing large changes between 1938 and 1996 were thoroughly discussed already by Tyler and Olsson (1997). They concluded that ca. 50\% of the biggest "losers" were species confined to tree-less fens, but several arable weeds and species confined to limnic habitats or managed heathlands were also in this group. In contrast, the biggest "winners" were found to be a mixture of species with widely different colonization histories and ecological demands, but with an overrepresentation of ruderals, garden weeds, recent immigrants, fertile hybrids, and species strongly favoured by high nitrogen availability or construction sites (Tyler and Olsson 1997).

Many of the species showing drastic changes in Scania during the 1900s have similar trends elsewhere in Sweden (e.g. Oredsson 1989; Maad et al. 2009; Sundberg 2014; Hedwall and Brunet 2016; Auffret and Thomas 2019) and other parts of Europe (Mennema et al. 1980-1989; Benkert et al. 1996; Rich and Woodruff 1996; Nielsen et al. 2019). However, most of the latter trends were observed in long-term studies over many decades. We know of no studies on a comparable geographic scale conducted over the very last decades with which the present results can be compared in terms of changes for individual species. Our results strongly advocate the need of performing broad-scale monitoring of floristic diversity over both short- and long-term time periods. 
Boreal coniferous forest

Acid nemoral deciduous forest

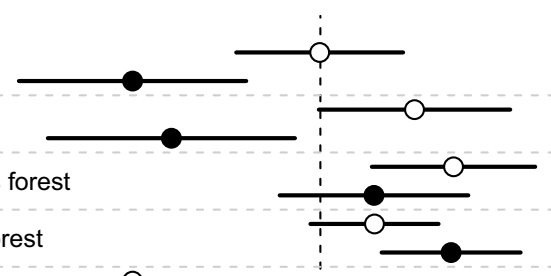

Intermediate nemoral deciduous forest

Base-rich nemoral deciduous forest

Raised bog

Acid swamp forest

Intermediate swamp forest

Base-rich swamp forest

Hedges, shrublands, wood margins, groves

Acid fen

Intermediate fen

Base-rich fen

Tall-herb wet meadow

Moist (seminatural) heath

Moist (seminatural) meadow

Moist (seminatural) calcareous meadow

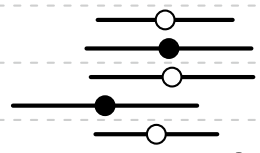

Dry (seminatural) heath

Dry (seminatural) meadow

Dry (seminatural) steppe-like meadow

Sand-steppe

Oligotrophic water

Mesotrophic water

Eutrophic water

Sandy sea-shore

Sea-shore meadows and marshes

Base-poor wastelands \& road verges

Base-rich wastelands \& road verges

Arable land

Gravelly/sandy yards, roads, pits etc.

Ruderal land
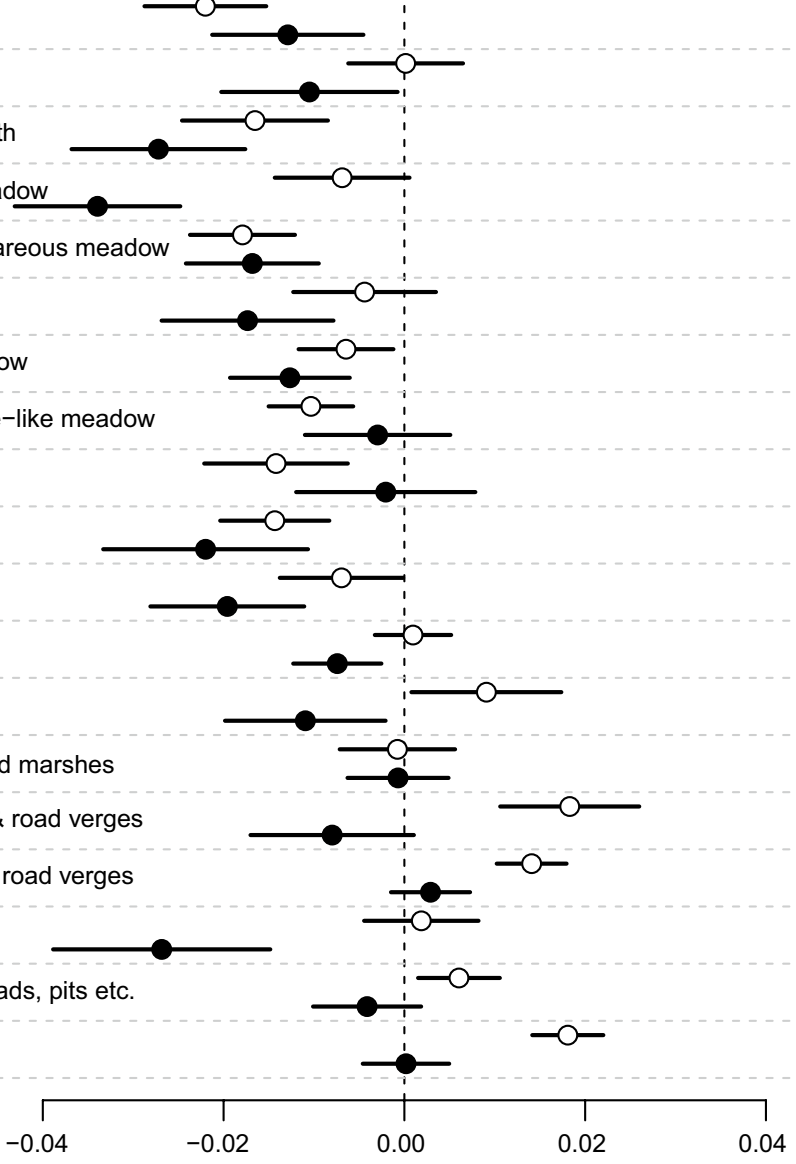

Mean change in frequency 
Fig. 5 Mean relative change in frequency per decade, with 95\% confidence intervals, of species associated with different vegetation types during the two time periods 1938-1995 (open circle) and 1987-2015 (filled circle). The number of species included for each vegetation type and the statistical significance of the change during each of the two time periods are indicated to the right. All species are included, but weighted by the number of grid squares occupied. That is, the changes shown here are mostly influenced by common species, whereas those shown in Fig. 4 of the main text are equally influenced by all species

We found a strong connection between the changes in frequency for individual species 1938-1996 and 1987-2015. However, it was only the decreasing species that tended to have the same trend during the two periods; the species shown to have increased during the 1900s did, on average, not continue to increase after this period (Fig. 1). This may be interpreted either as a sign that the drivers that caused species to decline during the 1900s are still acting, a scenario only partly corroborated by the results of Tyler et al. (2018), or as the result of an extinction debt or a general delay in how regional floras adapt to new conditions (Eriksson et al. 2002; Bertrand et al. 2011). Since most plant species are relatively long-lived, either as mature individuals or in the seed bank, and may thus persist as slowly decreasing populations under suboptimal conditions, the latter explanation appears more plausible. In contrast, apart from the consistent tendency of newly immigrated species to expand, the ecological drivers that cause species to increase appear to be largely different today compared to the 1900s. In view of the results of Tyler et al. (2018), Hedwall and Brunet (2016) and Auffret and Thomas (2019), it may be concluded that climate warming is currently a major driver for increasing species in the region. Indeed, in Scania the last decade has been $0.9-1.6{ }^{\circ} \mathrm{C}$ warmer with $60-80 \mathrm{~mm}$ higher precipitation than the reference period in the mid-1900s (based on climate data from the Swedish Meteorological and Hydrological Institute). In particular, current winter temperatures tend to stay slightly above rather than below the freezing point for most of the season, a factor with potentially large consequences for plant growth and survival (e.g. Birgander et al. 2012). Several epiphytic bryophytes with oceanic distributions, presumably strongly favoured by mild and wet winters have also shown remarkable increases and range expansions in Scania during recent decades (Tyler 2018). From a conservation perspective, when only records from earlier and longer time periods are available, it may generally be assumed that species shown to decline during the 1900 s are still at risk; by contrast, it should not be assumed that previously increasing species are still increasing.

However, the fact that the surveys here compared each encompassed two or more decades makes it somewhat difficult to associate the floristic changes observed with changes in the environment. Although we believe that such cases may at most be rare exceptions, we cannot rule out the possibility that some individual species may have experienced contrasting trends during the first and last years of the same survey period resulting in ambiguous conclusions when the accumulated survey results are compared. On the other hand, this may also be regarded as a strength of studies spanning long and partially overlapping time periods since erroneous conclusions based on short-term changes due to, e.g. the weather conditions of individual years or naturally cyclic changes in predator populations, can be avoided.

\section{Trends for vegetation types}

The vegetation types showing the largest average decreases of associated species (Figs. 4, 5) during the most recent decades are almost all tree-less, while the vegetation types performing the best are wooded or at least shaded by woody plants. With very few exceptions, 
Boreal coniferous forest

Acid nemoral deciduous forest
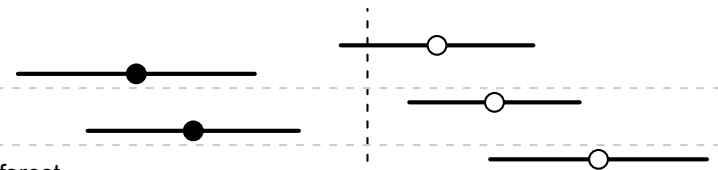

Intermediate nemoral deciduous forest

Base-rich nemoral deciduous forest

Raised bog

Acid swamp forest

Intermediate swamp forest

Base-rich swamp forest

Hedges, shrublands, wood margins, groves

Acid fen

Intermediate fen

Base-rich fen

Tall-herb wet meadow

Moist (seminatural) heath

Moist (seminatural) meadow

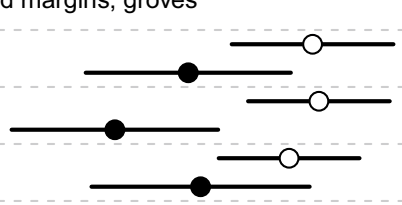

$76^{* * *}$

96 **

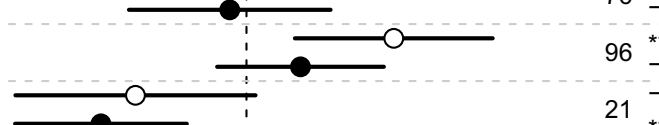

21

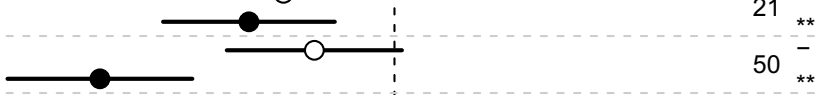

$50^{-}$

79

109

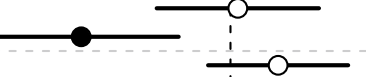

401 *

54 *

61 **

Moist (seminatural) calcareous meadow

Dry (seminatural) heath

Dry (seminatural) meadow

Dry (seminatural) steppe-like meadow

Sand-steppe

Oligotrophic water

Mesotrophic water

Eutrophic water

Sandy sea-shore

Sea-shore meadows and marshes

Base-poor wastelands \& road verges

Base-rich wastelands \& road verges

Arable land

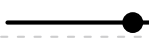

Gravelly/sandy yards, roads, pits etc.

Ruderal land

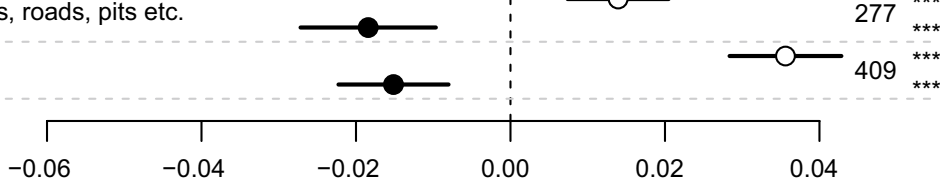

Mean change in frequency 
different types of forests represent climax ecosystems of the region, and thus, all of the declining vegetation types are to some degree dependent on human activities and management. It is widely established that the study region has undergone significant increases in forest cover (Cousins et al. 2005; Hedwall and Brunet 2016; free data from the Swedish Forest Inventory) and in the abundance of trees in the open agricultural landscape (Fredh et al. 2012; Blomberg 2013), combined with decreases in agricultural activities and in the number of grazing animals (cf. Cui et al. 2014; free data from the Swedish Board of Agriculture), especially in the less fertile upland areas. Thus, it may not come as a surprise that overgrowth and cessation of traditional management constitute major drivers of changes in the Scanian flora, as also shown by the analyses of Tyler et al. (2018) and that species thriving in shaded conditions increase relative to species of open managed habitats. Most of the forests of the region are either monospecific plantations or intensively managed for production of timber and other biomass, which is a potential threat to many organisms in forests (The Swedish Species Information Centre 2015). Yet, modern forestry practices appear to be less problematic for the vascular ground flora in Scania. Similar conclusions were reached by Maad et al. (2009) based on analyses of floristic data from more northern areas in Sweden.

The continuing concentration of arable land and pastures to the most productive areas is also reflected in our results. Species of fens, bogs, low-productive grasslands, oligotrophic waters and base-poor wastelands all show larger average declines than those of more productive vegetation types (Figs. 4, 5). Furthermore, among the arable weeds, the steepest declines seem to characterize species preferring less-productive soils (e.g. Raphanus raphanistrum, Brassica rapa subsp. campestris, Erysimum cheiranthoides, Crepis tectorum, Anthemis arvensis). Approximately $20-35 \%$ of all species associated with low-productive treeless vegetation such as heaths and acidic and intermediate fens have declined over the very last decades. This should be particularly alarming as these formerly widespread vegetation types and their associated species are important for a wide range of other organisms, in particular insects that provide pollination services (Carvell et al. 2006). Only political actions improving the profitability and reducing regulations imposed on farmers managing less-productive lands, combined with raising consumer demands for their products, can halt this process. Education campaigns directed towards land owners may also be beneficial since some species and habitats of protective value, but of little economic value, are today lost simply owing to the ignorance of the land owners.

The dramatic decrease documented for species in oligotrophic waters throughout northern Europe (Sand-Jensen et al. 2018) is most probably caused by the ongoing humification of previously clear acidic waters that has been observed throughout northern Europe (Kritzberg and Ekström 2012; Garmo et al. 2014). Submerged plants in humified waters rapidly disappear when light penetration of the water column decreases and the mineral sediments on the bottoms become buried under organic matter (Arts 2002). Since the underlying drivers of humification are still under debate (e.g. Kalbitz et al. 2017), it is difficult to propose counteractive measures, but increased disturbance from e.g. cattle grazing (Sand-Jensen et al. 2018) and reduced tree-cover along shorelines would most probably promote many of the plant species concerned. In contrast, plants of eutrophic waters show only a modest decrease during recent decades, numerically comparable to their increase observed during the 1900s (Fig. 4).

When comparing the relative rank of the changes estimated for different vegetation types between the two time periods considered (Figs. 4, 5), both similarities and dissimilarities become apparent. In this context, it has to be kept in mind that the grid-squares available for the first time period are not randomly distributed geographically; however, all 
inland vegetation types were reasonably well represented. All vegetation types that showed increases during the very last decades also increased in the 1900s, but it is clear that species of wooded or forested vegetation types have performed relatively better in recent years while species of open vegetations strongly influenced by human activities (e.g. waste lands and ruderal vegetation) show only minimal increases over the same time interval. Similarly, although the decreasing vegetation types remain largely the same, their internal rank order is much altered. It is, for example, notable that species of sand-steppes and steppe-like meadows, as well as rich fens, i.e. those vegetation types that have attained most attention and enjoyed most active measures from regional conservationists during recent decades (e.g. Bager and Persson 2009; Rosquist 2017), although still declining, appear to perform relatively better now than during the 1900s, while species of vegetation types that have received less attention, e.g. arable land, poor fens, oligotrophic waters, heaths and lowproductive meadows now comprise the most rapidly declining ones. There may be other explanations for this pattern, but it is tempting to conclude from our results that conservation measures actually do have positive effects also on broad-scale biodiversity.

The different approaches to calculate changes at the level of vegetation types attempted here may be expected to give somewhat different results. The mean over species change (Fig. 4) gives equal weight to all species, thus in effect up-weighting rare ones, while the "weighted approach" (Fig. 5) weights the changes proportionally to the frequency of the species. While it may be argued that rare species contribute only little to broad-scale biodiversity, up-weighting common ones may be problematic since these tend to be habitat generalists present in multiple vegetation types and thus not necessarily valid indicators for particular vegetation types. In particular, frequent species common to both widespread and rare vegetation types may provide false estimates of the trends of the latter. Furthermore, the weighted approach gives the same weight to all grid-squares, possibly introducing errors for those vegetation types that are geographically restricted to parts of the province while on the other hand being more relevant for changes at the scale of the province as a whole. However, for most vegetation types the two approaches suggest largely the same trends (compare Figs. 4, 5) and the same biggest winners and loosers. As expected, it is the geographically most restricted and species-poor vegetation types (boreal conifer forest, raised bog, sand-steppe and sandy sea-shores) that show the largest relative differences between the unweighted and the weighted estimates.

It must also be stressed that neither approach is able to differentiate between changes caused by changes in the areas covered by vegetation types and those caused by changes in the species richness of the vegetation types per area unit. In theory, a decrease in the area covered by a particular vegetation type can be compensated for by an increase in species richness at remaining sites. Still, we believe that mean changes and proportions of decreasing vs increasing species may be highly informative for giving priority to and choosing between conservation efforts.

\section{Consequences for general plant biodiversity}

While the proportion of rapidly declining vegetation types may be alarming, it must be stressed that several of the most species-rich vegetation types have performed well over the past decades, decreasing general losses of plant biodiversity at the landscape scale. In a recent study from Denmark overall plant species richness was found to have increased over the last centuries at the same time as the geographic diversity/differentiation of the species pool had decreased (Nielsen et al. 2019) and similar trends are suggested by a study with 
data from further north in Sweden (Auffret and Thomas 2019). Hedges, shrublands, wood margins, groves, waste lands, yards, gravel-pits, road verges and ruderal vegetation may not obtain the highest interest from conservationists, but together house more than one third of all species in Scania and all these vegetation types have either increased or remained stable in frequency. Thus, loss of vegetation types does not necessarily imply a reduction in total species diversity. Still, based on our data from the most recent decades (surveys 2 and 3), the number of decreasing species far outnumbers the number of increasing species. There may of course be differences in the completeness of all surveys, but the volunteers that participated in the field works of the two most recent surveys all got the same instructions, many of them participated during both surveys and the identity of critical species were checked by experts (cf. Tyler et al. 2018). In contrast, the comparison between the two first surveys conducted during the 1900s is inconclusive in this respect as only relative changes could be estimated. Still, a general reduction of species richness at the scale of the $2.5 \times 2.5 \mathrm{~km}$ grid-squares appear highly probable given the general intensification, upscaling and regional homogenisation of the land use seen during the last century (Bernes 2011-2012; Nielsen et al. 2019) and the results of local studies within the region (Oredsson 1989).

Acknowledgements Open access funding provided by Lund University. The Project Millora has been funded directly by the Lund Botanical Society and indirectly by Grants from the municipalities of Scania and Region Skåne. The engagement of all volunteer recorders and the members of the Society have been a prerequisite for the project and this study.

Author contributions TT and OO performed the analysis and drafted the manuscript, SA, LF, KAO and Å (together with TT) planned the project and administrated the data acquisition phase and all authors together prepared the final version of the manuscript.

Open Access This article is distributed under the terms of the Creative Commons Attribution 4.0 International License (http://creativecommons.org/licenses/by/4.0/), which permits unrestricted use, distribution, and reproduction in any medium, provided you give appropriate credit to the original author(s) and the source, provide a link to the Creative Commons license, and indicate if changes were made.

\section{References}

Andersson P-A, Weimarck G (1996) Floristic patterns and phytogeography of Skåne, S Sweden. Symb Bot Ups 31(3):239-264

Arts GHP (2002) Deterioration of Atlantic soft water macrophyte communities by acidification, eutrophication and alkalinisation. Aquat Bot 73:373-393. https://doi.org/10.1016/S0304-3770(02)00031-1

Auffret AG, Thomas CD (2019) Synergistic and antagonistic effects of land use and non-native species on community response to climate change. Glob Change Biol. https://doi.org/10.1111/gcb.14765

Bager H, Persson A (2009) Skånes Rikkärr. Länsstyr Skånes rapp 2009:41

Benkert P, Fukarek F, Korsch H (1996) Verbreitungsatlas der Farn- und Blütenpflanzen Ostdeutschlands. Jena

Berg $\AA$ (2002) Composition and diversity of bird communities in Swedish farmland-forest mosaic landscapes. Bird Study 49:153-165

Bernes C (2011-2012) Biological diversity in Sweden. Monitor 22. Swedish Environmental Protection Agency, Solna

Bernhardt-Römermann M, Baeten L, Craven DJ, De Frenne P, Hedl R, Lenoir J, Bert D, Brunet J, Chudomelova M, Decocq G, Dierschke H, Dirnbock T, Dorfler I, Heinken T, Hermy M, Hommel P, Jaroszewics B, Keczynski A, Kelly DL, Kirby KJ, Kopecky M, Macek M, Malis F, Mirtl M, Mitchell FJG, Naaf T, Newman M, Peterken G, Petrik P, Schmidt W, Standovar T, Toth Z, Van Calster H, Verstraeten G, Vladovic J, Vild O, Wulf M, Verheyen K (2015) Drivers of temporal changes in temperate forest 
plant diversity vary across spatial scales. Glob Change Biol 21:3726-3737. https://doi.org/10.1111/ gcb. 12993

Bertrand R, Lenoir J, Piedallu C, Riofrio-Dillon G, de Ruffray P, Vidal C, Pierrat JC, Gegout J-C (2011) Changes in plant community composition lag behind climate warming in lowland forests. Nature 479:517-520. https://doi.org/10.1038/nature10548

Birgander J, Rousk J, Olsson PA (2012) Activity of temperate grassland plants and symbiotic fungi during the winter-implications for community structure and carbon cycling in a changing climate. Nord $\mathbf{J}$ Bot 30:513-521

Blomberg P (2013) Skånes landskap i förändring. Swelo Mediaproduktion AB, Vinslöv. ISBN 978-91-637-3873-9

Carvell C, Roy DB, Smart SM, Pywell RF, Preston CD, Goulson D (2006) Declines in forage availability for bumblebees at a national scale. Biol Conserv 132:481-489

Cousins SAO, Auffret AG, Lindgren J, Trank L (2015) Regional-scale land-cover change during the 20th century and its consequences for biodiversity. Ambio 44(Suppl 1):17-27. https://doi.org/10.1007/ s13280-014-0585-9

Cui QY, Gaillard M-J, Lemdahl G, Stenberg L, Sugita S, Zernova G (2014) Historical land-use and landscape change in southern Sweden and implications for present and future biodiversity. Ecol Evol 4:3555-3570. https://doi.org/10.1002/ece3.1198

Eriksson O, Cousins SAO, Bruun HH (2002) Land-use history and fragmentation of traditionally managed grasslands in Scandinavia. J Veg Sci 13:743-748. https://doi.org/10.1111/j.1654-1103.2002.tb02102.x

Fredh D, Brostrom A, Zillen L, Mazier F, Rundgren M, Lageras P (2012) Floristic diversity in the transition from traditional to modern land-use in southern Sweden AD 1800-2008. Veg Hist Archaeobot 21:439-452. https://doi.org/10.1007/s00334-012-0357-z

Garmo ØA, Skjelkväle BL, de Wit HA, Colombo L, Curtis C, Fölster J, Hoffmann A, Hruska J, Hogasen T, Jeffries DS, Keller WB, Kram P, Majer V, Monteith DT, Paterson AM, Rogora R, Rzychon D, Steingruber S, Stoddard JL, Vuorenmaa J, Worsztynowicz A (2014) Trends in surface water chemistry in acidified areas in Europe and North America from 1990 to 2008. Water Air Soil Pollut 225:1880. https ://doi.org/10.1007/s11270-014-1880-6

Hedwall PO, Brunet J (2016) Trait variations of ground flora species disentangle the effects of global change and altered land-use in Swedish forests during 20 years. Glob Change Biol 22:4038-4047. https://doi. org/10.1111/gcb.13329

Jonason D, Milberg P, Bergman K-O (2010) Monitoring of butterflies within a landscape context in southeastern Sweden. J Nat Conserv 18:22-33. https://doi.org/10.1016/j.jnc.2009.02.001

Jonsell B (2004) Flora Nordica. General Volume. The Royal Swedish Academy of Sciences, Stockholm

Kalbitz K, Kaiser K, McDowell WH (2017) Nitrate decline unlikely to have triggered release of dissolved organic carbon and phosphate to streams. Glob Change Biol 23:2535-2536. https://doi.org/10.1111/ gcb.13659

Kritzberg ES, Ekström SM (2012) Increasing iron concentrations in surface waters-a factor behind brownification? Biogeosciences 9:1465-1478. https://doi.org/10.5194/bg-9-1465-2012

Maad J, Sundberg S, Stolpe P, Jonsell L (2009) Floristic changes during the 20th century in Uppland, east central Sweden. Svensk Bot Tidskr 103:67-104

Mennema J, Quené-Boterenbrood AJ, Plate CL (1980-1989) Atlas of the Netherlands Flora 1-3. London

Nielsen TF, Sand-Jensen K, Dornelas M, Bruun HH (2019) More is less: net gain in species richness, but biotic homogenization over 140 years. Ecol Lett. https://doi.org/10.1111/ele.13361

Olsson K-A, Tyler T (2007) Annotated list of species with distribution-maps. In: Tyler T, Johansson H, Olsson K-A, Sonesson M (eds) Floran i Skåne-Arterna och deras utbredning. Lunds Botaniska Förening, Lund, pp 126-726

Oredsson A (1989) Förändringar av floran i Matteröds socken i norra Skåne mellan 1964 och 1989. Svensk Bot Tidskr 84:293-311

Persson H, Tyler T (2007) The geological prerequisites of the flora of Skåne. In: Tyler T, Johansson H, Olsson K-A, Sonesson M (eds) Floran i Skåne - Arterna och deras utbredning. Lunds Botaniska Förening, Lund, pp 7-17

R Core Team (2019) R: A language and environment for statistical computing. R foundation for statistical computing. Vienna, Austria. http://www.R-project.org/

Rich TCR, Woodruff ER (1996) Changes in the vascular plant floras of England and Scotland between 1930-1960 and 1987-1988: the BSBI monitoring scheme. Biol Conserv 75:217-229

Rosquist G (2017) Åtgärdsprogram för sandstäpp, 2015-2019. Swedish Environmental Protection Agency reports 6676 , pp $1-70$

Sand-Jensen K, Bruun HH, Nielsen TF, Christiansen DM, Hartvig P, Schou JC, Baastrup-Spohr L (2018) The dangers of being a small, oligotrophic and light demanding freshwater plant across a spatial and 
historical eutrophication gradient in southern Scandinavia. Front Plant Sci 9, Article 66. https://doi. org/10.3389/fpls.2018.00066

Sundberg S (2014) Boreal plant decline in southern Sweden during the twentieth century. N J Bot 4:76-84. https://doi.org/10.1179/2042349714Y.0000000045

The Swedish Species Information Centre (2015) Rödlistade arter i Sverige 2015. ArtDatabanken SLU, Uppsala

Tyler T (2007) Some climatic data on Skåne. In: Tyler T, Johansson H, Olsson K-A, Sonesson M (eds) Floran i Skåne - Arterna och deras utbredning. Lunds Botaniska Förening, Lund, pp 5-6

Tyler T (2018) Oceanic epiphytes - the primary winners of Global Change. Bot Not 151(2):25-30

Tyler T (2019) The sandy pine forests of Åhus_-a paradise for botanists focused on woody plants or a nightmare for conservationists? Bot Not 152(2):1-11

Tyler T, Olsson K-A (1997) Changes in the flora of Scania during the years 1938-1996-a statistical analysis of the results of two large-scale surveys. Svensk Bot Tidskr 91:143-185

Tyler T, Karlsson T, Milberg P, Sahlin U, Sundberg S (2015) Invasive plant species in the Swedish flora: developing criteria and definitions, and assessing the invasiveness of individual taxa. Nord $\mathrm{J}$ Bot 33:300-317. https://doi.org/10.1111/njb.00773

Tyler T, Herbertsson L, Olsson PA, Fröberg L, Olsson K-A, Svensson Å, Olsson O (2018) Climate warming and land-use changes drive broad-scale floristic changes in Southern Sweden. Glob Change Biol 24:2607-2621. https://doi.org/10.1111/gcb.14031

Weimarck H, Weimarck G (1985). Atlas över Skånes Flora. Stockholm

Publisher's Note Springer Nature remains neutral with regard to jurisdictional claims in published maps and institutional affiliations. 